University of Nebraska - Lincoln

DigitalCommons@University of Nebraska - Lincoln

July 1998

\title{
Thermal stability and nanostructure of CoCrPt longitudinal recording media
}

\author{
Mingjun $\mathrm{Yu}$ \\ University of Nebraska - Lincoln \\ Mary F. Doerner \\ IBM Storage Systems Division, San Jose, CA \\ David J. Sellmyer \\ University of Nebraska-Lincoln, dsellmyer@unl.edu
}

Follow this and additional works at: https://digitalcommons.unl.edu/physicssellmyer

Part of the Physics Commons

Yu, Mingjun; Doerner, Mary F.; and Sellmyer, David J., "Thermal stability and nanostructure of CoCrPt longitudinal recording media" (1998). David Sellmyer Publications. 71.

https://digitalcommons.unl.edu/physicssellmyer/71

This Article is brought to you for free and open access by the Research Papers in Physics and Astronomy at DigitalCommons@University of Nebraska - Lincoln. It has been accepted for inclusion in David Sellmyer Publications by an authorized administrator of DigitalCommons@University of Nebraska - Lincoln. 


\title{
Thermal Stability and Nanostructure of CoCrPt Longitudinal Recording Media
}

\author{
Mingjun Yu \\ Center for Materials Research \& Analysis and Behlen Laboratory of Physics, University of Nebraska, Lincoln, NE 68588-0113 \\ Mary F. Doerner \\ IBM Storage Systems Division, 5600 Cottle Road, San Jose, CA 95193 \\ David J. Sellmyer \\ Center for Materials Research \& Analysis and Behlen Laboratory of Physics, University of Nebraska, Lincoln, NE 68588-0113
}

\begin{abstract}
We report a systematic study of activation volumes and their correlation with physical grain sizes and thermal stability in CoCrPt media fabricated by magnetron sputtering. Different underlayers and CoCrPt layer thicknesses were used to provide a range of lateral grain sizes, $M_{r} \delta$ (product of remanence $M_{r}$ and film thickness $\delta$ ) values, and remanence coercivities. Two methods, namely the field-sweep-rate dependence of coercivity and measurements of magnetic viscosity and irreversible susceptibility, were used to determine the activation volumes and the results obtained from the two methods are in reasonable agreement. For $\mathrm{CoCrPt}$ layer thickness from $10 \mathrm{~nm}$ to $27 \mathrm{~nm}$, the activation volumes of these films range from about $3 \times 10^{-18} \mathrm{~cm}^{3}$ to $5 \times 10^{-18} \mathrm{~cm}^{3}$, which indicate that these films are thermally stable. Furthermore, for most samples the activation volumes are close to the volumes of the physical CoCrPt grains. This suggests that the magnetic grains in these films switch almost independently. Films with physical grain sizes small enough to approach thermal instability are also discussed.
\end{abstract}

Index Terms-CoCrPt, longitudinal recording media, nanostructure, thermal stability.

\section{INTRODUCTION}

The areal density in magnetic recording has been increasing at a compounded growth rate of about $60 \%$ per year and such an increase is predicted to continue in the near future [1], [2]. At present, $1 \mathrm{Gbit} / \mathrm{in}^{2}$ hard drives are commercially available and a $5 \mathrm{Gbit} / \mathrm{in}^{2}$ hard drive has been demonstrated [3]. The increase of areal density decreases the bit size. Because the number of magnetic grains per bit must be kept at a certain level due to signal-to-noise ratio requirement, grain size has to decrease to allow the increase in areal density. But there is a limit on grain size due to thermal fluctuation (instability). If the grains are too small, they will become superparamagnetic at room temperature and unable to record any information.

For an isolated single-domain particle with certain anisotropy, its volume $\mathrm{V}$ determines its thermal stability. But for a real magnetic system consisting of many magnetic grains, it is the magnetic activation (or switching) volume $\mathrm{V}^{*}[4]$ instead of $\mathrm{V}$ that determines the thermal stability (see later text). We report the results on $V^{*}$ measurements by two different methods, their relationship with physical grain volume $\mathrm{V}$ and the associated thermal stability of $\mathrm{CoCr}_{22} \mathrm{Pt}_{8}$ and $\mathrm{CoCr}_{22} \mathrm{Pt}_{14}$ films on $\mathrm{CrV}_{\mathrm{x}}$ underlayer $(\mathrm{x}=0,20,50)$. Results on thin $\mathrm{CoCr}_{22} \mathrm{Pt}_{14}$ films with physical grain volumes small enough to approach thermal instability are also reported.

Manuscript received October 16, 1997.

M. Yu, 402-472-8925, fax 402-472-2879, myu@unlinfo.unl.edu; M. F Doerner, 408-256-4977, fax 408-256-2410, doerner@sjevm5.vnet.ibm.com.

This work was supported by NSIC, NSF/DMR-9623992, and CMRA

\section{BACKGROUND THEORIES ON THERMAL STABILITY AND ACTIVATION VOLUME}

For a single domain particle, its magnetization $\mathrm{M}$ decays due to thermal fluctuation. At temperature $\mathrm{T}$ the relaxation time $\tau$ is given by [5]:

$$
1 / \tau=f_{0} \exp \left(-E_{B} / k_{B} T\right)
$$

where $\mathrm{f}_{0}\left(\sim 10^{9} \mathrm{~Hz}\right)$ is the attempt frequency and $\mathrm{E}_{\mathrm{B}}$ is the height of the energy barrier. For a particle with uniaxial anisotropy constant $\mathrm{K}_{\mathrm{u}}, \mathrm{E}_{\mathrm{B}}$ is given by:

$$
\mathrm{E}_{\mathrm{B}}=\mathrm{K}_{\mathrm{u}} \mathrm{V}\left(1-\mathrm{H} / \mathrm{H}_{\mathrm{A}}\right)^{2} \approx \mathrm{K}_{\mathrm{u}} \mathrm{V},
$$

where $H$ is the field applied in the opposite direction of the particle's magnetization and $\mathrm{H}_{\mathrm{A}}$ is the anisotropy field $\left(\mathrm{H}_{\mathrm{A}}=\right.$ $2 \mathrm{~K}_{\mathrm{u}} / \mathrm{M}_{\mathrm{s}}, \mathrm{M}_{\mathrm{s}}$ is the saturation magnetization). When $\mathrm{H} \ll \mathrm{H}_{\mathrm{A}}$, the approximation can be made. The superparamagnetic (or thermal instability) limit may be defined by setting $\tau=100 \mathrm{~s}$, which implies from (1), (2) that

$$
\mathrm{K}_{\mathrm{u}} \mathrm{V} / \mathrm{k}_{\mathrm{B}} \mathrm{T}=25 \text {. }
$$

In a real system $\mathrm{E}_{\mathrm{B}}$ (or $\tau$ ) has a distribution, and a logarithmic decay is usually observed in certain time range:

$$
\mathrm{M}(\mathrm{H}, \mathrm{t})=\mathrm{M}_{0}-\mathrm{S}(\mathrm{H}) \operatorname{lnt}
$$

where $\mathrm{M}_{0}$ is a constant independent of time and $\mathrm{S}$ is the magnetic viscosity.

Activation volume $\mathrm{V}^{*}$ is the unit volume of magnetic moments that switch together in magnetization reversal. The relationship between $V^{*}$ and $V$ is illustrated in [6]. $V^{*} \approx V$ simply means that the grains switch independently: $V^{*}>V$ suggests that several grains aligned together by exchangecoupling switch together. This group of grains forms a magnetic cluster and magnetically acts like one grain with volume $V^{*} . V^{*}<V$ indicates incoherent rotations. In any case we see that the volume of magnetic moments switching together is $\mathrm{V}^{*}$. This is confirmed by the linear relationship between $M_{s} V^{*}$ and media noise [7]. So in magnetic reversal processes it is $V^{*}$ instead of $V$ that should be considered and $\mathrm{V}$ in (2), (3) is replaced with $\mathrm{V}^{*}$ in the rest of this paper.

Magnetic viscosity $\mathrm{S}$ is related to activation volume $\mathrm{V}^{*}$ as shown by Street and Woolley [4]:

$$
\mathrm{V}^{*}=\mathrm{k}_{\mathrm{B}} \mathrm{T} \chi_{\mathrm{irr}} / \mathrm{M}_{\mathrm{S}} \mathrm{S}
$$

where $\chi_{\text {irr }}$ is the irreversible susceptibility (derivative of DC demagnetization curve). The $\chi_{\text {irr }}(\mathrm{H})$ curve is very similar to the $\mathrm{S}(\mathrm{H})$ curve. Usually, the maximum values of $\mathrm{S}$ and $\chi_{\mathrm{irr}}$ are used in (5) to determine $\mathrm{V}^{*}$. Bruno, et al [8] related $\mathrm{V}^{*}$ to 
the field sweep-rate dependence of coercivity $\mathrm{H}_{\mathrm{c}}$ :

$$
\mathrm{H}_{\mathrm{c}}=\text { Const. }+\left(\mathrm{k}_{\mathrm{B}} \mathrm{T} / \mathrm{M}_{\mathrm{s}} \mathrm{V}^{*}\right) \ln (\mathrm{dH} / \mathrm{dt}) \text {, }
$$

providing a convenient method to determine $\mathrm{V}^{*}$. In this paper we use both methods to determine $\mathrm{V}^{*}$ if applicable.

\section{EXPERIMENTAL METHODS}

Two sets of CoCrPt media disk samples were fabricated on NiP-plated Al substrates by magnetron sputtering. For the first set $24 \mathrm{~nm}$ of $\mathrm{CoCr}_{22} \mathrm{Pt}_{8}$ and $27 \mathrm{~nm}$ of $\mathrm{CoCr}_{22} \mathrm{Pt}_{14}$ were deposited onto $\mathrm{CrV}_{\mathrm{x}}$ underlayer $(\mathrm{x}=0,20,50)$, respectively. The magnetic layer thickness $\delta$ was chosen to make the $\mathrm{M}_{\mathrm{r}} \delta$ values around $0.73 \mathrm{memu} / \mathrm{cm}^{2}$. For the second set $\mathrm{CoCr}_{22} \mathrm{Pt}_{14}$ layers of different thicknesses $(17.5,13.0,10.2,7.5,5.5 \mathrm{~nm})$ were deposited onto $20 \mathrm{~nm} \mathrm{CrV}_{20}$ intermediate layers, which were deposited onto $60 \mathrm{~nm} \mathrm{NiAl} \mathrm{underlayers.} \mathrm{All} \mathrm{magnetic}$ measurements were done on an alternating gradient force magnetometer (AGFM) at $\mathrm{T}=300 \mathrm{~K}$, which is used as the temperature for discussion throughout this paper. Lateral grain sizes were estimated from grazing incidence X-ray spectra (GIXS) and transmission electron microscopy (TEM) analysis.

\section{RESULTS AND DISCUSSION}

\section{A. $\mathrm{CoCr}_{22} \mathrm{Pt}_{8}$ and $\mathrm{CoCr}_{22} \mathrm{Pt}_{14}$ films on $\mathrm{Cr} \mathrm{V}_{x}$ underlayer}

Microstructural and magnetic parameters $\left(M_{r} \delta, H_{c r}=r e-\right.$ manence coercivity, $\mathrm{H}_{\mathrm{c}}, \mathrm{d}=$ grain size, $\mathrm{V}^{*}$, and $\mathrm{d}^{*}=$ $\left.\left(4 \mathrm{~V}^{*} / \pi \delta\right)^{1 / 2}\right)$ of these films are listed in Table $\mathrm{I}$. The measured $\mathrm{H}_{\mathrm{c}}(\mathrm{dH} / \mathrm{dt})$ data and the corresponding fits (Fig. 1) indicate that (6) describes these samples well. The $V^{*}$ values were determined from the slopes of the fits. The $\mathrm{V}^{*}$ values were also calculated using (5) from the $S$ and $\chi_{\text {irr }}$ values of the $\mathrm{CoCr}_{22} \mathrm{Pt}_{14} / \mathrm{Cr}$ and $\mathrm{CoCr}_{22} \mathrm{Pt}_{14} / \mathrm{CrV}_{50}$ films for comparison. The magnetization of the $\mathrm{CoCr}_{22} \mathrm{Pt}_{14} / \mathrm{Cr}$ film decays logarithmically (Fig. 2) for $t>100 \mathrm{~s}$ as described by (4). The corresponding $\mathrm{S}(\mathrm{H})$ curve, obtained by fitting the curves in Fig. 2, and $\chi_{\text {irr }}(\mathrm{H})$ curve are shown in Fig. 3. The two curves are very similar except for a small shift in field, which comes from the difference in measurement time. Activation volumes

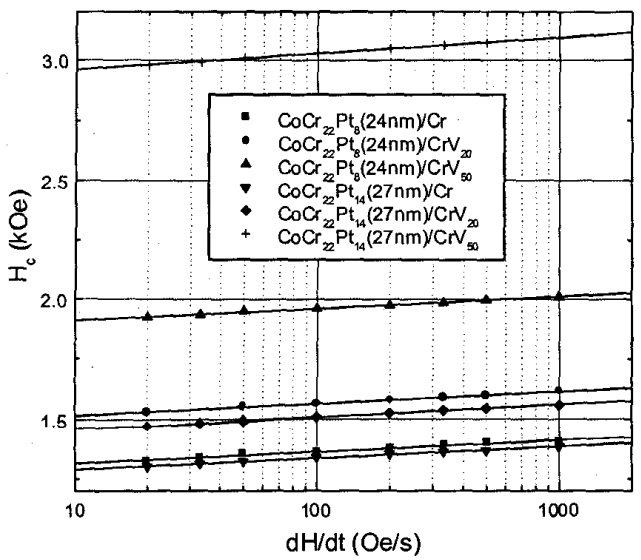

Fig. 1. Field sweep-rate $(\mathrm{dH} / \mathrm{dt})$ dependence of coercivity $\left(\mathrm{H}_{\mathrm{c}}\right)$ of $\mathrm{CoCr}_{22} \mathrm{Pt}_{8}(24 \mathrm{~nm}) / \mathrm{CrV}_{\mathrm{x}}$ and $\mathrm{CoCr}_{22} \mathrm{Pt}_{14}(27 \mathrm{~nm}) / \mathrm{CrV}_{\mathrm{x}}$ films.

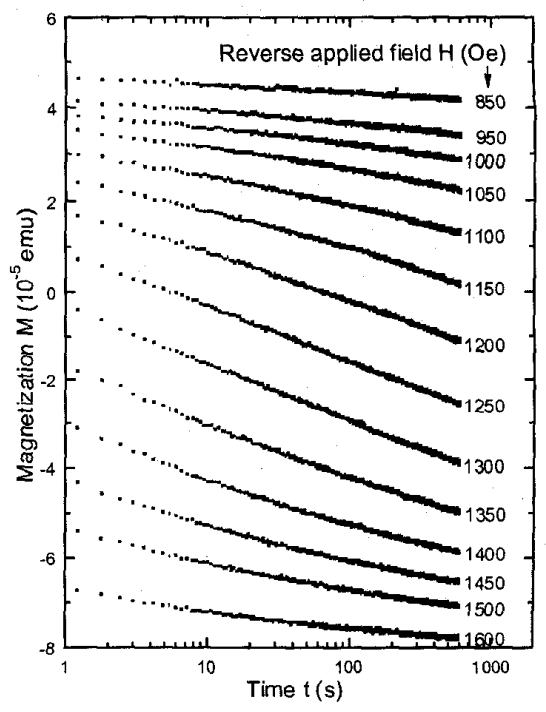

Fig. 2. Magnetization decay curves of $\mathrm{CoCr}_{22} \mathrm{Pt}_{14}(27 \mathrm{~nm}) / \mathrm{Cr}$ film.

obtained by the two methods are in reasonable agreement. Using a cylindrical magnetic grain model, a lateral magnetic grain size $\mathrm{d}^{*}$ can be calculated from $\mathrm{V}^{*}$ and $\delta$. It turns out that $d^{*}$ and $d$, the physical lateral grain size estimated from GIXS analysis, are fairly close. This indicates that the CoCrPt grains switch almost independently. The $\mathrm{K}_{\mathrm{u}} \mathrm{V}^{*} / \mathrm{k}_{\mathrm{B}} \mathrm{T}$ values of these films were estimated to be around 200, far above the superparamagnetic limit set in (3). The relative magnetization decay rate $R$ is defined in this paper as the $S$ value at $\mathrm{H}_{\mathrm{cr}} / 2$ reverse applied field normalized by $\mathrm{M}_{\mathrm{r}}$ in $\log _{10} \mathrm{t}$ scale. For $\mathrm{CoCr}_{22} \mathrm{Pt}_{14} / \mathrm{Cr}$ and $\mathrm{CoCr}_{22} \mathrm{Pt}_{14} / \mathrm{CrV}_{50}$ films $\mathrm{R}$ is less than $1 \%$ per decade. Both results indicate that these films have very good thermal stability.

\section{B. $\mathrm{CoCr}_{22} \mathrm{Pt}_{14} / \mathrm{CrV} \mathrm{V}_{20}(20 \mathrm{~nm}) / \mathrm{NiAl}(60 \mathrm{~nm})$ films}

The CoCrPt layers have thicknesses of 17.5, 13.0, 10.2, 7.5 , and $5.5 \mathrm{~nm}$. TEM analysis on films with $\delta=10.2$ and $17.5 \mathrm{~nm}$ indicates that both films consist of $\mathrm{CoCrPt}$ grains with lateral grain size of about $15 \mathrm{~nm}$. These films were deposited on the same underlayers, so they are all expected to have about $15 \mathrm{~nm}$ lateral grain sizes. Microstructural and

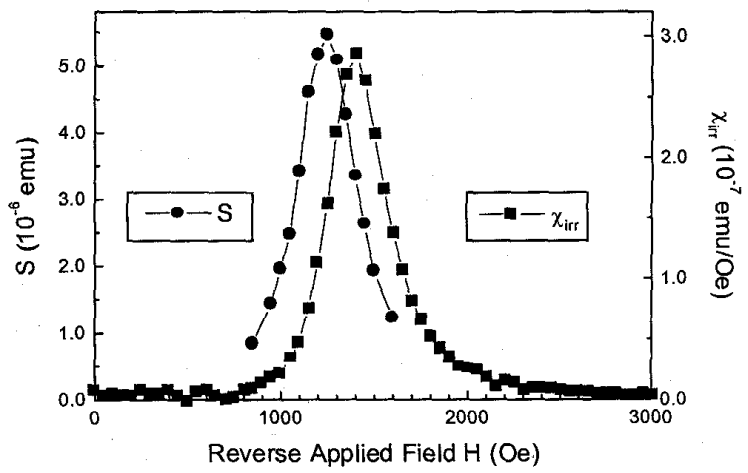

Fig. 3. Magnetic viscosity $S(H)$ and irreversible susceptibility $\chi_{\text {irr }}(H)$ curves of $\mathrm{CoCr}_{22} \mathrm{Pt}_{14}(27 \mathrm{~nm}) / \mathrm{Cr}$ film. 
TABLE I

Mrcrostructural and Magnetic Parameters of CoCrPt/CrV $\mathrm{CFILMS}_{\mathrm{x}}$

\begin{tabular}{lcccc}
$\begin{array}{c}\text { Film } \\
\text { Specification }\end{array}$ & $\begin{array}{c}\mathrm{H}_{\mathrm{cr}} \\
(\mathrm{kOe})\end{array}$ & $\begin{array}{c}\mathrm{d} \\
(\mathrm{nm})\end{array}$ & $\begin{array}{c}\mathrm{V}^{*} \\
\left(10^{-18} \mathrm{~cm}^{3}\right)\end{array}$ & $\begin{array}{c}\mathrm{d}^{*} \\
(\mathrm{~nm})\end{array}$ \\
\hline $\mathrm{CoCr}_{22} \mathrm{Pt}_{8}(24 \mathrm{~nm}) / \mathrm{Cr}$ & 1.39 & 14 & 5.2 & 17 \\
$\mathrm{CoCr}_{22} \mathrm{Pt}_{8}(24 \mathrm{~nm}) / \mathrm{CrV}_{20}$ & 1.60 & 16 & 5.0 & 16 \\
$\mathrm{CoCr}_{22} \mathrm{Pt}_{8}(24 \mathrm{~nm}) / \mathrm{CrV}_{50}$ & 2.03 & 21 & 4.8 & 16 \\
$\mathrm{CoCr}_{22} \mathrm{Pt}_{14}(27 \mathrm{~nm}) / \mathrm{Cr}$ & 1.42 & 16 & $5.1(5.7)$ & 16 \\
$\mathrm{CoCr}_{22} \mathrm{Pt}_{14}(27 \mathrm{~nm}) / \mathrm{CrV}_{20}$ & 1.72 & 16 & 4.9 & 15 \\
$\mathrm{CoCr}_{22} \mathrm{Pt}_{14}(27 \mathrm{~nm}) / \mathrm{CrV}_{50}$ & 3.17 & 22 & $3.5(4.2)$ & 13
\end{tabular}

The $V^{*}$ values were obtained with $(6)$ and those in parenthesis were obtained with (5).

magnetic parameters of these films are listed in Table II. Table II and Fig. 4 show that $\mathrm{H}_{\mathrm{c}}$ and $\mathrm{H}_{\mathrm{cr}}$ decrease sharply as $\delta$ decreases from 17.5 to $5.5 \mathrm{~nm}$. Fig. 4 also indicates that there exists a "soft" phase $\left(\mathrm{H}_{\mathrm{c}}<100 \mathrm{Oe}\right)$ whose moment is comparable with that of the $7.5 \mathrm{~nm}$ CoCrPt layer. It was found that this soft phase comes from the NiP layer. The low $\mathrm{H}_{\mathrm{c}}$ of the NiP layer increasingly brings down the $\mathrm{H}_{\mathrm{c}}$ of the "composite" magnetic film as its moment gradually dominates the total moment of the film with the decrease of $\delta$ (see Fig. 4). $\mathrm{H}_{\mathrm{cr}}$ and $\chi_{\text {irr }}$ are affected little by the moment of the NiP layer, which is soft and reversible. The decrease of $\mathrm{H}_{\mathrm{cr}}$ is probably due to the thermal instability (see text below) and some other possible microstructural changes. Because the moment of the NiP layer is thermally stable and $S$ is obtained near coercivity, $S$ is also increasingly affected with decreasing $\delta$. $V^{*}$ obtained using (5) is therefore also affected. This may be the reason that as $\delta$ decreases, $V^{*}$. does not decrease, according to the cylindrical model, as fast as it should when $\delta>10.2 \mathrm{~nm}$, and to the contrary increases (see the parenthesized $\mathrm{V}^{*}$ values in Table II) when $\delta<10.2 \mathrm{~nm}$. Although the relative decay rate $\mathrm{R}$ is also affected, it still provides an indication of thermal stability. The increase of $\mathrm{R}$ with the decrease of $\delta$ suggests that these films are becoming thermally unstable. When $\delta=5.5 \mathrm{~nm}, \mathrm{R}>16 \%$ per decade, indicating that this film is already thermally unstable. The thermal instability of these films is probably a reason for the decrease of $\mathrm{H}_{c}$ and $\mathrm{H}_{\mathrm{cr}}$ with the decrease of $\delta$.

\section{CONCLUSIONS}

Both methods of determining activation volume used in this paper can provide fairly reliable results on activation volume, which is a better indication of thermal stability than physical grain volume. Both $\mathrm{CoCr}_{22} \mathrm{Pt}_{8}(24 \mathrm{~nm}) / \mathrm{CrV}_{\mathrm{x}}$ and $\mathrm{CoCr}_{22} \mathrm{Pt}_{14}(27 \mathrm{~nm}) / \mathrm{CrV}_{\mathrm{x}}(\mathrm{x}=0,20,50)$ films were found to

TABLE II

Microstructural and MAGNeTtC Parameters of $\mathrm{CoCr}_{22} \mathrm{Pt}_{14}(8) / \mathrm{CrV}_{20} / \mathrm{NiAl}$ FILMS

\begin{tabular}{cccccc}
\hline $\begin{array}{c}\delta \\
(\mathrm{nm})\end{array}$ & $\begin{array}{c}\mathrm{M}_{\mathrm{r}} \delta \\
\left(\mathrm{memu} / \mathrm{cm}^{2}\right)\end{array}$ & $\begin{array}{c}\mathrm{H}_{\mathrm{cr}} \\
(\mathrm{kOe})\end{array}$ & $\begin{array}{c}\mathrm{H}_{\mathrm{c}} \\
(\mathrm{kOe})\end{array}$ & $\begin{array}{c}\mathrm{V}^{*} \\
\left(10^{-18} \mathrm{~cm}^{3}\right)\end{array}$ & $\begin{array}{c}\mathrm{R} \\
(\text { per decade) }\end{array}$ \\
\hline 17.5 & 0.53 & 2.76 & 2.16 & 3.3 & $3 \%$ \\
13.0 & 0.39 & 2.44 & 1.91 & 2.9 & $3 \%$ \\
10.2 & 0.31 & 1.84 & 1.38 & 2.6 & $4 \%$ \\
7.5 & 0.23 & 1.39 & 0.70 & $(2.9)$ & $>5 \%$ \\
5.5 & 0.17 & 0.40 & 0.30 & $(5.0)$ & $>16 \%$ \\
\hline \multicolumn{5}{l}{ The V* values were obtained with (5) and those in parenthesis have large }
\end{tabular}

deviation from the "real" values (see text)

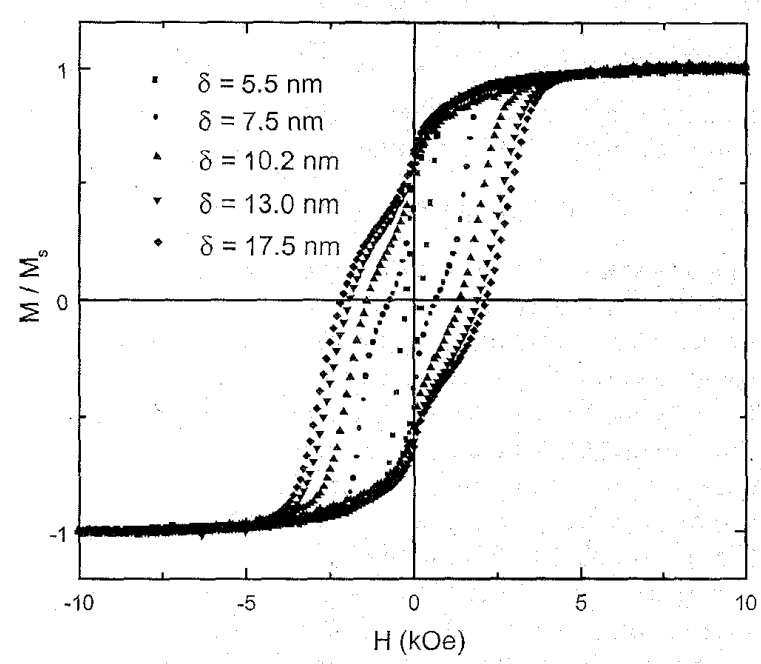

Fig. 4. Hysteresis loops of $\mathrm{CoCr}_{22} \mathrm{Pt}_{14}(\delta) / \mathrm{CrV}_{20} \mathrm{NiAl}$ films.

have activation volumes close to physical grain volumes and therefore the magnetic grains switch almost independently. These films also have high thermal stability. The coercivity of $\mathrm{CoCr}_{22} \mathrm{Pt}_{14}(\delta) / \mathrm{CrV}_{20} / \mathrm{NiAl}$ films $(\delta=17.5,13.0,10.2,7.5$, $5.5 \mathrm{~nm}$ ) decreases sharply as $\delta$ decreases. This may be caused by both the increasing thermal instability and the increasing effect of the soft moment of the NiP layer as $\delta$ decreases. When the $\mathrm{CoCr}_{22} \mathrm{Pt}_{14}$ layer thickness is decreased to $5.5 \mathrm{~nm}$, it becomes thermally unstable at room temperature.

\section{ACKNOWLEDGMENT}

The authors would like to thank Prof. Y. Liu (TEM analysis), Prof. R. D. Kirby, and Dr. Z.S. Shan of CMRA at U. of Nebraska and Dr. Chester Qian (GIXS analysis) of SSD of IBM for their generous help.

\section{REFRENCES}

[1] E. Grochowski and D. A. Thompson, "Outlook for maintaining areal density growth in magnetic recording," IEEE Trans. Magn., vol. 30 , pp. 3797,1995

[2] J. L. Simonds, "Magnetoelectronics today and tomorrow," Phys. Today, vol. 48, No. 4, pp. 26, 1995

[3] C. Tsing, T. Lin, S. MacDonald, M. Pinarbasi, N. Robertson, H. Sanfini, M. Doerner, T. Reith, L. Vo, T. Diola; and P. Arnett, " $5 \mathrm{~Gb} / \mathrm{in}^{2}$ recording demonstration with conventional AMR dual element heads \& thin film disks," IEEE Trans. Magn., vol. 33, pp. 2866, 1997.

[4] R. Street and J. C. Woolley, "A study of magnetic viscosity," Proc. Phys. Soc., vol. A62, pp. 562, 1949

[5] L. Néel, "Théorie du trainage magnétique," Ann. Geophys., vol. 5, pp 99, 1949.

[6] D. J. Sellmyer, M. Yu, R. A. Thomas, Y. Liu, and R. D. Kirby, "Nanoscale design of films for extremely high density recording," Phys. Low Dim. Struc., to be published.

[7] K. Yamanaka, T: Yamamoto, K. Tanahashi, N. Iraba, Y. Hosoe, Y. Uesaka, and M. Futamoto, "Fluctuation fields and medium noise in CoCrTa and CoCrPt films," J. Magn. Magn. Mater, vol. 152, pp. 411, 1996.

[8] P. Bruno, G. Bayreuther, P. Beauvillain, C. Charppert, G. Lugert, D. Renard, J. P. Renard and J. Seiden, "Hysteresis properties of ultrathin ferromagnetic films," J. Appl. Phys., vol. 68, pp. 5759, 1990. 